\title{
MANAGEMENT SERVER BERBASIS SMS GATEWAY STUDI KASUS PADA GCM EDNOVATION YOGYAKARTA
}

\author{
Arif Hidayatullah, Hero Wintolo \\ Jurusan Teknik Informatika \\ Sekolah Tinggi Teknologi Adisutjipto Yogyakarta \\ informatika@stta.ac.id
}

\begin{abstract}
Trust is a key factor in online communication, a hosting that can be accessed quickly and almost never had an error would indicate that the hosting has managed seriously in serving consumers. Therefore a hosting requires regular maintenance and handling of error as soon as possible before consumers feel the effects. On the other side hosting providers need to protect their systems to provide access to others who don't have the right and protect it using a firewall. Those two things became very difficult to do simultaneously considering the speed and ease of access contrary to the security of the hosting. There are many ways in which the administrators to handling this case. One of many ways is create a private network that can only be accessed from within the network, during time for treatments this private hosting use SMS as medium, this media have been chosen because it can directly installed within the private network.By using this sms media, administrator can make application that can do the repair server directly without being worried with the danger of the public internet network, because application running on a private network. Applications can also be built more complex so that application will help administrator to monitor condition of the server and repair errors on the server, administrators can do it anywhere without being dependent on a stable internet connection.
\end{abstract}

Keywords : Management Server, SMS Gateway, Troubleshooting.

\section{Pendahuluan}

Seorang administrator yang bertugas memantau dan merawat seluruh layanan yang ditanamkan pada server harus dapat memastikan semua layanan dapat berjalan dengan baik. Hal ini menjadi tidak efisien dan menyulitkan bagi seorang administrator mengingat banyaknya jumlah server dan berbagai macam service atau layanan yang harus dipantau setiap saat oleh seorang administrator. Kesulitan lainnya adalah rules dari keamanan server yang tidak memungkinkan untuk melakukan perbaikan dari jaringan yang tidak dikenali dan penggunaan teknologi cloud computing yang menggunakan jaringan private untuk pemprosesan internal sehingga mengharuskan perbaikan melalui jaringan internal. Dengan memanfaatkan SMS Gateway memungkinkan dibangunnya sistem internal yang melakukan pemantauan dan perbaikan secara otomatis dengan memanfaatkan pesan singkat/SMS sebagai media pelaporan dan trigger dari perbaikan.

\section{Kajian Pustaka}

Veena K. Katankar dan Dr. V. M. Thakare (2010) dalam jurnal internasional yang diterbitkan menjelaskan dasar dari desain jaringan SMS. Dengan desain jaringan SMS yang digunakan memungkinkandibangunnya aplikasi di dalam sebuah komputer yang dapat 
bertugas sebagai SMS Gateway. Aplikasi SMS Gateway ini memungkinkan pengguna melakukan pengiriman dan menerima pesan.

Yudi Wiharto (2011), dalam jurnal nasional yang diterbitkan menjelaskan implementasi SMS Gateway sebagai media penyampaian informasi masal. Pesan yang ingin disampaikan dikirim dengan format tertentu ke SMS Gateway, aplikasi ini meneruskan pesan dengan mengambil nomor telepon tujuan dari database.

Mario Agapito Arizald Gobel (2011), merancang suatu sistem untuk mendeteksi suatu gangguan, deteksi didasarkan pada menyaring port pada jaringan internet melalui server proxy. Sistem SMS Gateway dipilih sebagai media penyampaian informasi gangguan.

\section{Metode Penelitian}

\subsection{Metode pengumpulan data}

Metode kepustakaan adalah suatu metode pengumpulan data melalui buku-buku literatur ataupun dokumen yang berhubungan dengan management serverdan SMS Gateway.

\subsection{Perancangan perangkat lunak}

Perancangan aplikasi menggunakan konsep OOP (Object Oriented Programming) yaitu suatu metode perancangan program yang berorientasi pada objek. Kebutuhan perangkat keras, perangkat lunak dan Jaringan yang digunakan dalam pembuatan aplikasi ini sebagai berikut:

1. Intel Core i3

2. RAM 8 GB

3. Harddisk500 GB

4. Sistem Operasi Ubuntu 12.04

5. Mysql

6. Netbeans

7. PHP5

8. Bash shell

9. Codeigniter

10. Modem GSM

11. RouterMikrotik

\subsubsection{Analisis Sistem}

Konsep kerja dari management server berbasis SMS Gateway adalah dengan menanamkan aplikasi monitoring server, SMS Gateway dan prosedur problem solving langsung di dalam jaringan internal atau private sebuah sistem cloud computing. Dari keseluruhan kerja sistem tersebut administrator dapat melakukan control dan perbaikan hanya dengan menggunakan media SMS. 


\subsubsection{Perancangan Aplikasi}

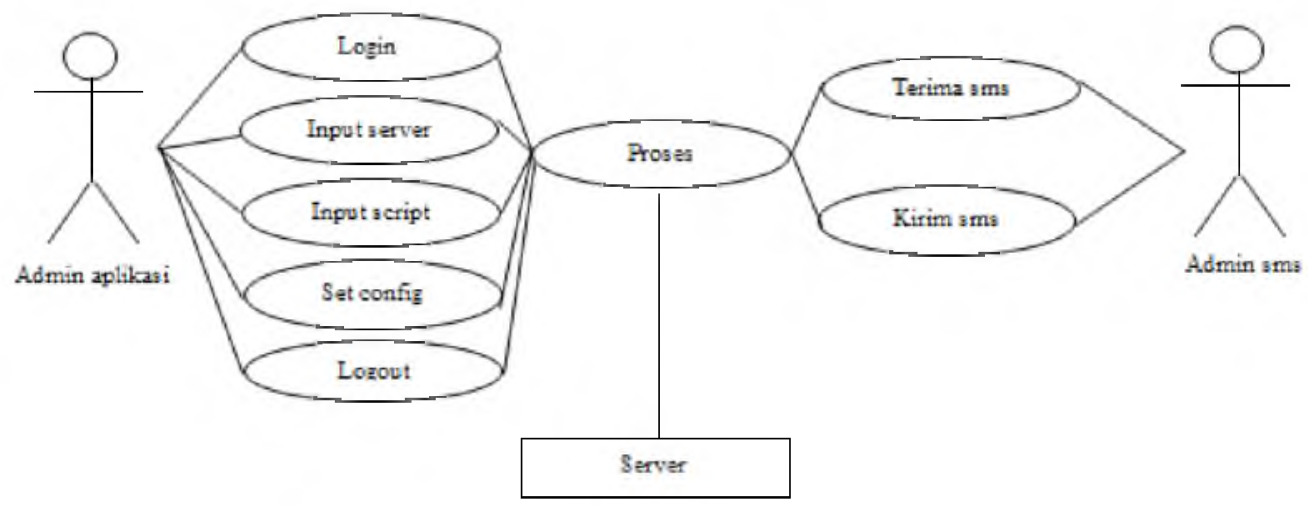

Gambar 1 Diagram Use case

Perancangan ini menjelaskan penerapan SMS gateway sebagai media untuk pelaporan dan sebagai media perbaikan server yang dapat dilakukan dengan menambahkan daftar perintah yang dapat ditangani oleh aplikasi. Proses penggunaan aplikasi dapat dilihat pada gambar 1.

\subsubsection{Perancangan Antar Muka}

Perancangan antar muka ini akan digunakan untuk melakukan interaksi antar pemakai dan aplikasi, seperti penambahkan prosedur problem solving dan konfigurasi, sehingga memudahkan untuk melakukan pengaturan aplikasi. Perancangan antar muka ini menggunakan Native Templating, dengan menyusun Form-form yang ada menjadi sebuah template library sehingga dari beberapa form yang ada akan ditangani oleh sebuah view yang akan mempermudah penggunaan kembali area tersebut, adapun area-area tersebut header, top menu, content, right menu dan footer.

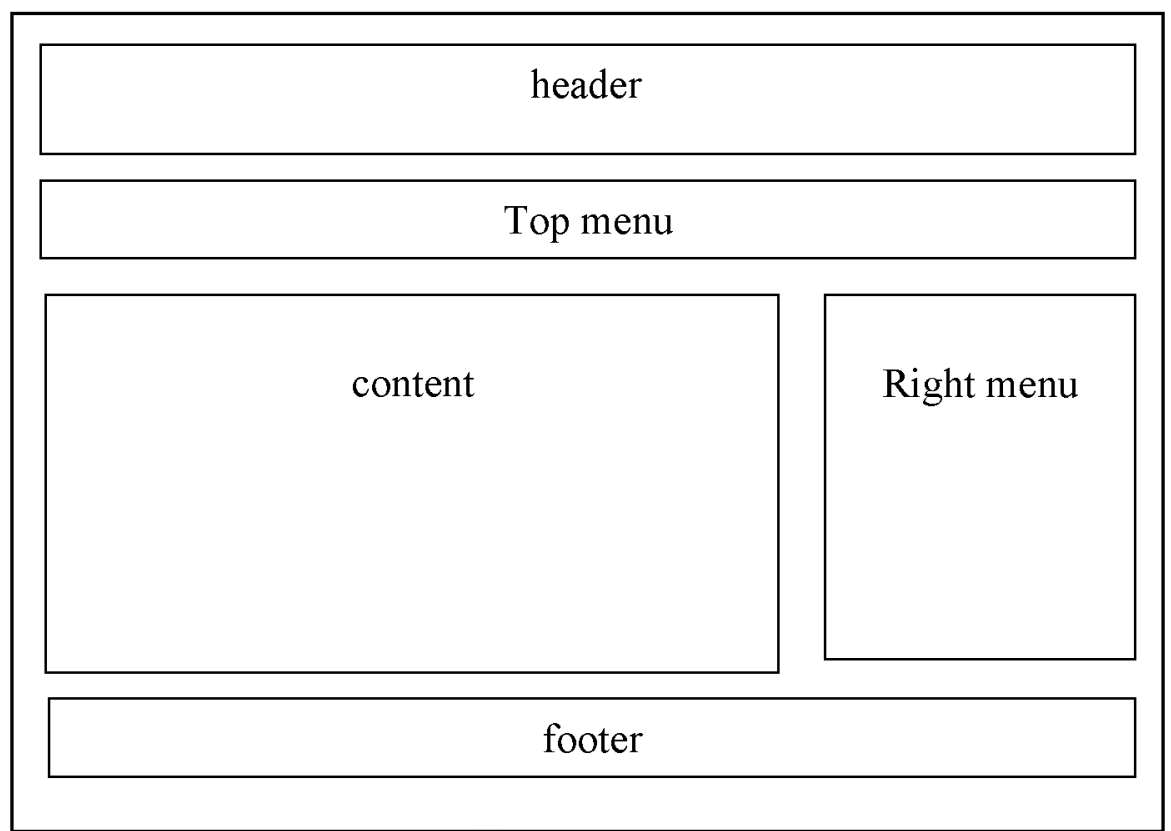

Gambar 2 Perancangan Formnative 


\subsubsection{Hubungan Antar Tabel}

Logical Record Structure (LRS) adalah representasi dari struktur record-record pada tabel-tabel yang terbentuk dari hasil antar himpunan entitas. Pada Gambar 3 menjelaskan hubungan dari masing-masing table database, dimana table configuration berhubungan dengantabel server dan table script. Sedangkan table user dan tabel status tidak memiliki hubungan dengan tabel lain.

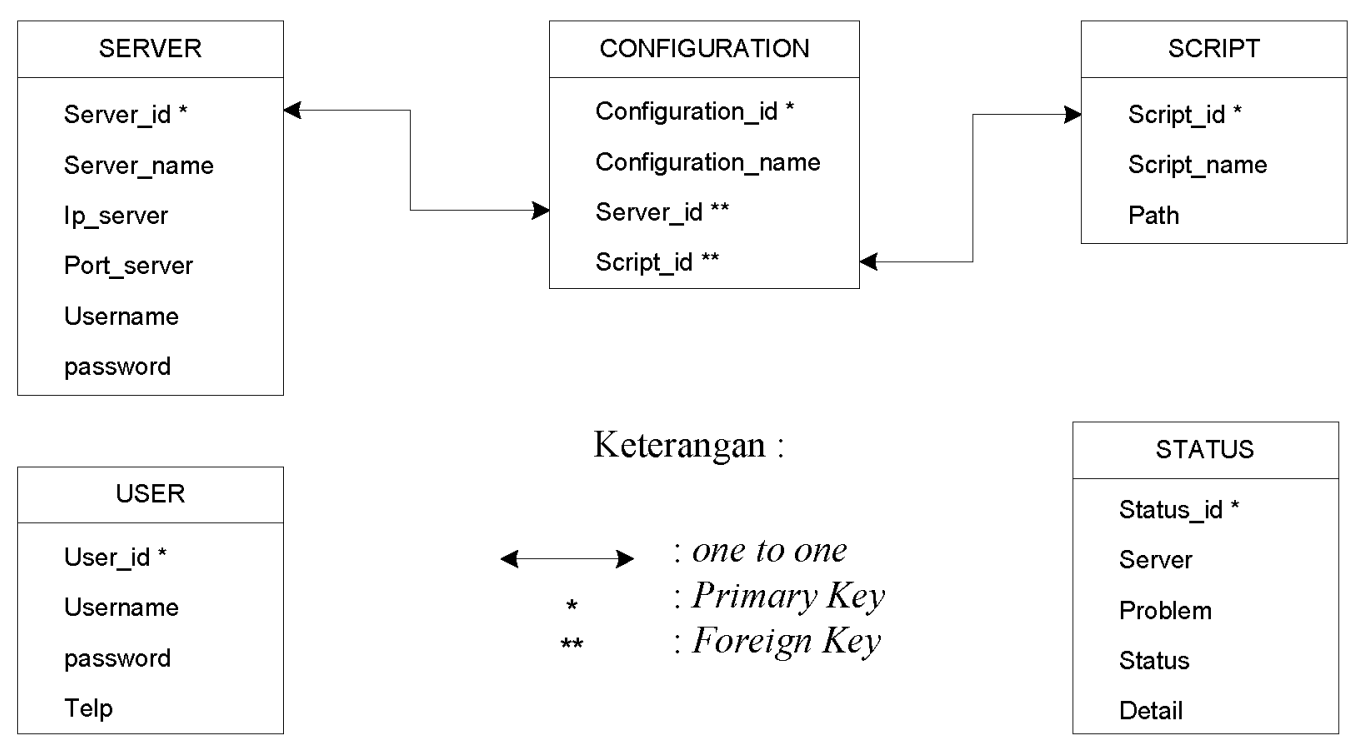

Gambar 3 Relasi Antar Tabel

\section{Hasil dan Pembahasan}

Tahapan selanjutnya dari penelitian ini uji fungsi berupa pengujian menerima SMS dari aplikasi saat terjadi masalah pada server, pengiriman SMS untuk melakukan pengecekan kondisi server dan pengujian aplikasi dalam melakukan perbaikan server melalui pengiriman SMS.

\subsection{Uji Fungsi SMS Problem}

Pengujian ini menggunakan sampel pada saat salah satu web server mengalami error, error pada server ini terjadi karena keterbatasan kemampuan menangani request dari pengguna pada saat-saat tertentu yang membuat service terhenti. kondisi ini akan langsung memicu aplikasi monitoring menginformasikan aplikasi SMS Gateway untuk mengirimkan pesan SMS bahwa server tersebut mengalami masalah. Pada Gambar 4 menunjukkan pesan yang diterima oleh administrator. 


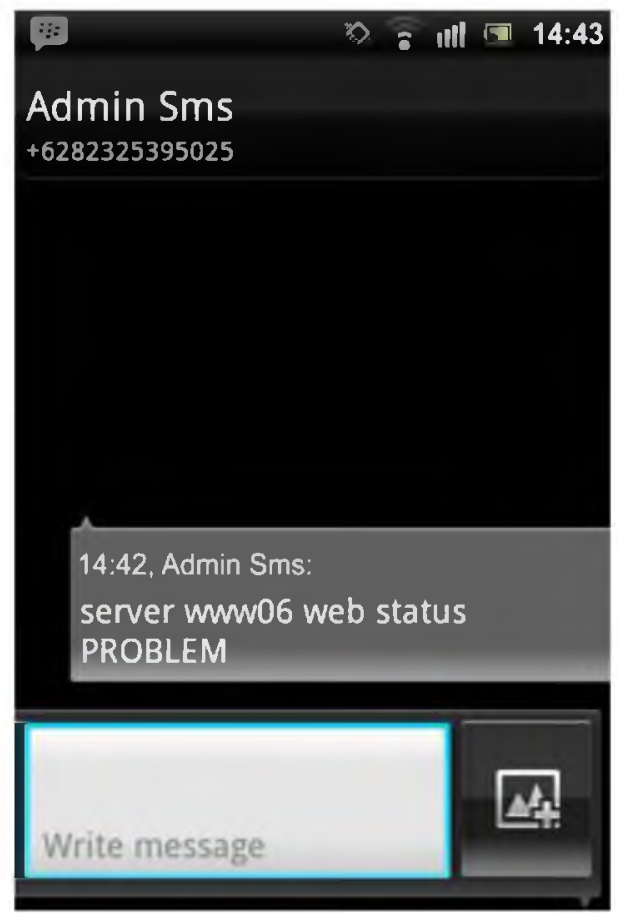

Gambar 4 Pesan Problem Yang Diterima Administrator

\subsection{Uji Fungsi Pengecekan Kondisi Server}

Pada pengujian ini administrator melakukan pengirim pesan SMS ke aplikasi untuk mengetahui semua status service yang berjalan pada server yang dimaksud. Format pengiriman pesan untuk pengecekan ini adalah "status" spasi "nama server", tanpa tanda petik. Pada Gambar 5 adalah gambar yang menunjukkan pesan yang dikirim dan yang diterima oleh administrator.

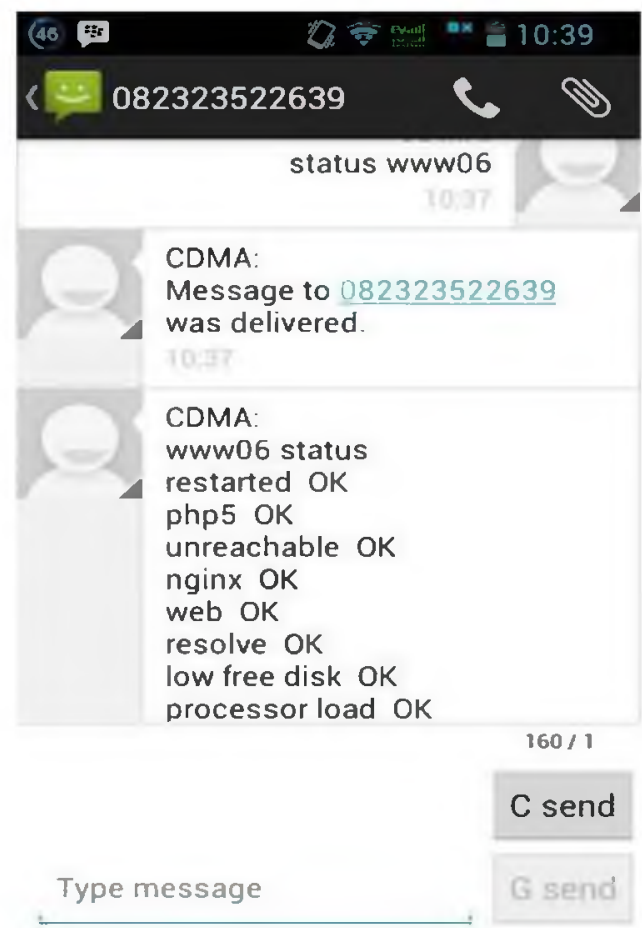

Gambar 5 Cek Status Server www06 


\subsection{Uji Fungsi Perbaikan Server}

Pada pengujian perbaikan server ini administrator mengirimkan pesan SMS untuk memicu prosedur problem solving untuk masalah tersebut. Format pesan yang berlaku adalah format pada konfigurasi aplikasi saat prosedur ini di install pada server. Pada prosedur problem solving ini aplikasi melakukan pengambilan source code pada server repository selanjutnya mendistribusikan source code tersebut ke semua web server. Pada Gambar 6 merupakan log dari aplikasi saat prosedur problem solving dijalankan.

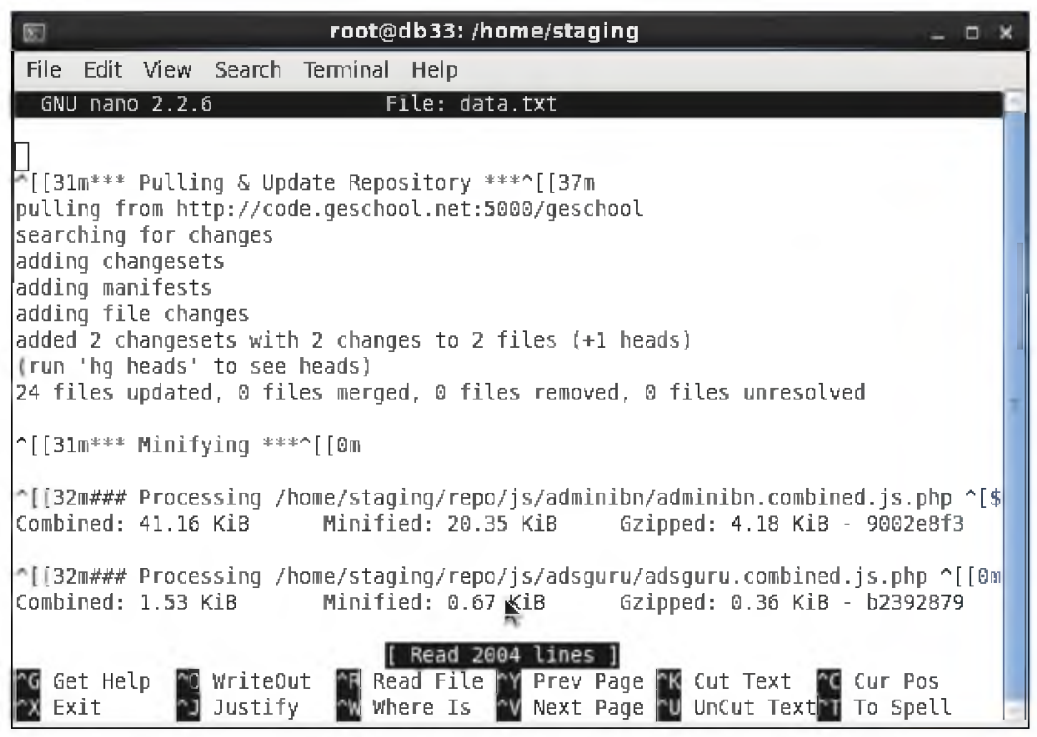

Gambar 6 Log Aplikasi

\subsection{Analisa Hasil}

Pengujian pertama adalah pengujian dimana aplikasi akan mengirimkan pesan SMS saat server mengalami error, hasil dari pengujian ini menunjukkan aplikasi berhasil mengirimkan pesan saat terjadi error.

Pengujian kedua adalah pengujian dimana administrator melakukan pengecekan kondisi semua service pada server yang dimaksud, hasil dari pengujian ini menunjukkan bahwa aplikasi dapat melakukan pengecekan kondisi server dan mengirimkan informasi tersebut ke administrator.

Pengujian ketiga adalah pengujian dimana server mengalami error dan administrator mengirimkan pesan SMS untuk mengaktifkan prosedur problem solving dari error tersebut.

Dari pengujian yang telah dilakukan dengan 3 pengujian tersebutdi peroleh kesimpulan bahwa aplikasi telah berhasil diimplementasikan dan telah berjalan dengan baik sesuai dengan tujuan pembuatan aplikasi.

\section{Penutup}

\subsection{Kesimpulan}

Dari hasil pengujian yang dilakukan dalam penelitian ini dapat disimpulkan bahwa :

1. Aplikasi yang dirancang telah terbukti dapat membantu administrator untuk menangani perbaikan error dengan menggunakan media SMS.

2. SMS dapat dimanfaatkan untuk media perbaikan yang hanya dapat dilakukan dari dalam jaringan private yang berada di dalam firewall. 


\subsection{Saran}

Perlu lebih dikembangkan prosedur problem solving dari server sehingga aplikasi dapat memiliki lebih banyak script perbaikan dan tugas seorang administrator jaringan menjadi lebih mudah.

\section{Daftar Pustaka}

Andi, 2012, Administrasi Jaringan Dengan Linux Ubuntu 11, Penerbit Wahana Komputer, Semarang.

Athailah, Panduan Singkat Menguasai Router Mikrotik untuk Pemula, 2013, Penerbit Media Kita, Bogor.

Ibnu Daqiqil Id, M.TI., 2011, Framework Codeigniter, Sebuah Panduan dan Best Practice, diakses pada tanggal 24 mei 2012.

Loka Dwiartara., Menyelam dan Menaklukkan Samudra PHP, Penerbit ilmuwebsite.com, diakses pada tanggal 24 Mei 2012.

Mario Agapito Arizald Gobel., 2012, Notification Of Security Threats On The Internet Proxy Server Is A Server-based Short Message Service (SMS), Jurnal Compiler, Volume I Nomor 1 April 2012, Sekolah Tinggi Teknologi Adisutjipto, Yogyakarta.

Veena K. Katankar dan Dr. V. M. Thakare., 2010, Short Message Service using SMS Gateway, International Journal on Computer Science and Engineering (IJCSE), Volume II Nomor IV April 2010.

Wiswakarma, K., 2010, 9 Langkah Menjadi Master Framework Codeigniter, Penerbit Loka Media, Bekasi.

Yudi Wiharto., 2011, Implementasi SMS Gateway Sebagai Media Penyampaian Informasi Masal, Jurnal Teknomatika, Volume I Nomor 1 Januari 2011. 
